\title{
INCLUSÃO DE MATERIAL HERBORIZADO EM METACRILATO PARA ESTUDOS DE ANATOMIA VEGETAL ${ }^{1}$
}

\author{
Renata Maria Strozi Alves Meira² e Fabiano Machado Martins ${ }^{3}$
}

\begin{abstract}
RESUMO - As técnicas usuais empregadas no processamento de materiais herborizados são limitantes porque não permitem reproduzir um laminário permanente e porque o registro dos resultados é temporário. Em estudos de anatomia aplicada à taxonomia, muitas vezes, é necessário utilizar exsicatas. Este trabalho teve como objetivo testar a utilização de metacrilato (Historesin, Leica) na preparação e inclusão de material herborizado, visando a obtenção de laminário permanente. Foram utilizadas folhas de plantas herborizadas do gênero Senecio Tourn. ex L. (Asteraceae), previamente reidratadas $\mathrm{em}_{2} \mathrm{O}$ e armazenadas em etanol 70\%. As amostras foram desidratadas em série etanólica e submetidas à (1v:1v) mistura de AE 95\% e resina pura. Durante a infiltração, com resina pura, o material foi submetido a vácuo durante 72 horas. Os blocos foram cortados em micrótomo de avanço automático, com navalhas de aço descartáveis, e os cortes foram corados com azul-de-toluidina ( $\mathrm{pH} 4,0$ ). As lâminas foram montadas em Permount. O laminário permanente obtido apresentou qualidade superior à dos produzidos pelas técnicas usuais, pois foi possível obter cortes seriados, com espessura determinada. Essa técnica possibilitou otimizar a obtenção de cortes, a partir de pequenos fragmentos de exsicatas.
\end{abstract}

Palavras-chave: Anatomia vegetal, taxonomia, plantas herborizadas, lâminas permanentes e Senecio.

\section{THE INCLUSION OF HERBALIZED MATERIAL USING METHACRYLATE FOR PLANT ANATOMY STUDIES}

\begin{abstract}
The usual herbalized material processing techniques are limited due to the difficulties to produce permanent slide collections, and to register permanent results. In studies of taxonomy-applied anatomy, it is often necessary to use herbarium specimens. The objective of this study was to test methacrylate (Historesin, Leica) in the preparation and inclusion of herbalized materials to obtain a permanent slide collection. Herbalized leaves from the genus Senecio Tourn. ex L. (Asteraceae) were used, after being submitted to re-dehydration in ethanol $70 \%$. The samples were dehydrated in an ethanol series and submitted to a mixture of AE 95\% plus pure resin $(1 v: 1 v)$. The embbeding process in pure resin was submitted to a vaccum during 72 hours. The blocks were cut in an automatic progress microtome, using disposable steel razors and the cuts stained with Toluidine Blue pH 4.0. The slides were mounted in Permount. The permanent slide collection obtained showed high quality, compared with those obtained by the usual techniques, because the cuts were seriate; cut thickness could be determined allowing the use of few samples for the analysis of the material.
\end{abstract}

Key words: Plant anatomy, taxonomy, herbalized specimens, permanent slides and Senecio.

A anatomia vegetal tem sido uma importante ferramenta para a taxonomia (Solereder 1908; Metcalfe \& Chalk, 1950, 1979, 1983; Metcalfe, 1987; Cutler \& Gregory, 1998; Judd, 1999). As plantas são coletadas e o registro da espécie é garantido pela produção de exsicatas e pela sua posterior manutenção em herbários. Logo, a organização taxonômica das plantas depende destes registros (Radford \& Dickson, 1974; Bridson \& Forman, 1998). Em alguns taxa, a sua raridade ou a dificuldade em recoletá-lo implica, necessariamente, trabalhar com exsicatas.

1 Recebido para publicação em 23.4.2002.

Aceito para publicação em 19.2.2003.

2 Profa ${ }^{a}$ do Dep. Biologia Vegetal da Universidade Federal de Viçosa - UFV, 36571-000 Viçosa-MG; <rmeira@mail.ufv.br>.

${ }^{3}$ Biólogo, mestrando em Botânica, Dep. de Biologia Vegetal da UFV, bolsista CAPES. 
A análise anatômica de plantas herborizadas pode ser a única fonte de material para estudos de anatomia aplicados à taxonomia (Castro et al., 1997; Scatena et al., 1999; Teixeira et al., 2000). Entretanto, o material tornase frágil por ter sido submetido a temperaturas elevadas para sua secagem. As técnicas usuais para se trabalhar com materiais herborizados implicam reversão do processo de herborização. Inicia-se pela reidratação por meio de fervura em água destilada e posterior distensão com solução de hidróxido de potássio (Smith \& Smith, 1942). O material pode, então, ser conservado em etanol $70 \%$. Estas amostras são cortadas à mão livre, para montagem de lâminas provisórias. Não é recomendada a inclusão em parafina para obtenção de cortes em micrótomo e montagem de lâminas permanentes, pois estas técnicas implicam desidratação do material, o que provoca retração das células e dos tecidos.

Assim, as técnicas usuais de preparação de materiais herborizados impõem limitações, pois o tempo de duração do laminário é reduzido, não se pode garantir a espessura do corte, além do fato de elas não permitirem a obtenção de cortes seriados. Um outro aspecto a ser enfatizado é a necessidade de cortar vários fragmentos para obter um número reduzido de cortes de qualidade para análise ao microscópio.

Este trabalho teve como objetivo testar a utilização de metacrilato (Historesin, Leica) na inclusão de material herborizado e obtenção de laminário permanente.

Foram utilizadas plantas herborizadas do gênero Senecio Tourn. ex L. (Asteraceae), depositadas nos herbários OUPR (UFOP) e CESJ (UFJF) sob os números: OUPR 25094 - Senecio emilioides Sch. Bip.; CESJ 1629 - Senecio leptoschizus Bong.; OUPR 25277 - Senecio stigophlebius Baker.

As folhas foram submetidas ao processo de reversão da herborização (Smith \& Smith, 1942) e estocadas em etanol $70 \%$.

A porção média (nervura central e margem) foi isolada e desidratada na seqüência de etanol 85 e $95 \%$, sendo mantida por 2 horas em cada. Posteriormente, as amostras foram submetidas à mistura de etanol $95 \%$ e resina pura (Historesin Leica, preparada conforme instrução do fabricante), na proporção de 1v:1v, por 8 horas. A infiltração foi feita com resina pura, em um dessecador submetido a vácuo, e em intervalos de 24 horas foram realizadas três

R. Árvore, Viçosa-MG, v.27, n.1, p.109-112, 2003 trocas de resina pura, totalizando 72 horas. A resina pura foi misturada ao polimerizador, conforme as instruções do fabricante, e as amostras emblocadas em moldes plásticos. Os blocos foram cortados em um micrótomo rotativo de avanço automático (RM 2155 - Leica), com navalhas de aço descartáveis. Cortes de $10 \mu \mathrm{m}$ de espessura foram distendidos em banheira contendo água destilada, aderidos em lâminas histológicas, mantidas em seqüência conhecida, e corados com azul-de-toluidina pH 4 (Vidal, 1977). As lâminas foram secas em estufa a $34{ }^{\circ} \mathrm{C}$ e montadas em resina sintética Permount. Não é recomendada a utilização de xilol nem a de álcool nesta etapa, pois estes compostos podem interferir na coloração e na aderência dos cortes à lâmina.

Algumas amostras das mesmas porções foliares foram preparadas conforme a metodologia usual. Os cortes foram feitos à mão livre e corados com safranina solução aquosa e azul-de-astra (Gerlach, 1969). As lâminas foram montadas em gelatina glicerinada e lutadas com esmalte.

Para análise e documentação fotográfica, utilizouse um fotomicroscópio Olympus AX 70 equipado com sistema U-Photo.

A folha de Senecio emilioides (Figura 1a, b) é hipoestomática e recoberta por epiderme uniestratificada, o mesofilo é dorsiventral e os feixes são vasculares colaterais. Ductos secretores estão presentes, associados ou próximos ao floema, tanto na nervura central quanto nas laterais.

Em Senecio leptoschizus (Figura 1c, d) as folhas são pinactisectas e na porção mediana verifica-se que os estômatos estão presentes em ambas as faces (folhas anfiestomáticas) e que a epiderme, que é uniestratificada, forma uma depressão na face adaxial, onde se localizam tricomas. O mesofilo é dorsiventral e os feixes são colaterais. Ductos secretores estão presentes, associados ou próximos ao floema, nas nervuras.

Hidatódios foram evidenciados na margem da folha de Senecio stigophlebius, sendo constituídos por vascularização exclusivamente xilemática, por epitema aclorofilado e por poros (Figura 1e, f).

Os cortes obtidos dos materiais incluídos em historesina (Figura 1a, c, e) são mais nítidos e possibilitam descrições anatômicas mais seguras que as daqueles submetidos à técnica convencional (Figura 1b, d, f).

Entre as vantagens resultantes deste método, destacam-se: a produção de laminário permanente, que 
poderá servir como testemunho do estudo; os cortes podem ser seriados; a espessura do corte é determinada; e poucas amostras são suficientes para se proceder à análise e interpretação anatômica. A qualidade do laminário obtido por essa técnica é superior, comparada à daqueles obtidos pelas técnicas usuais.
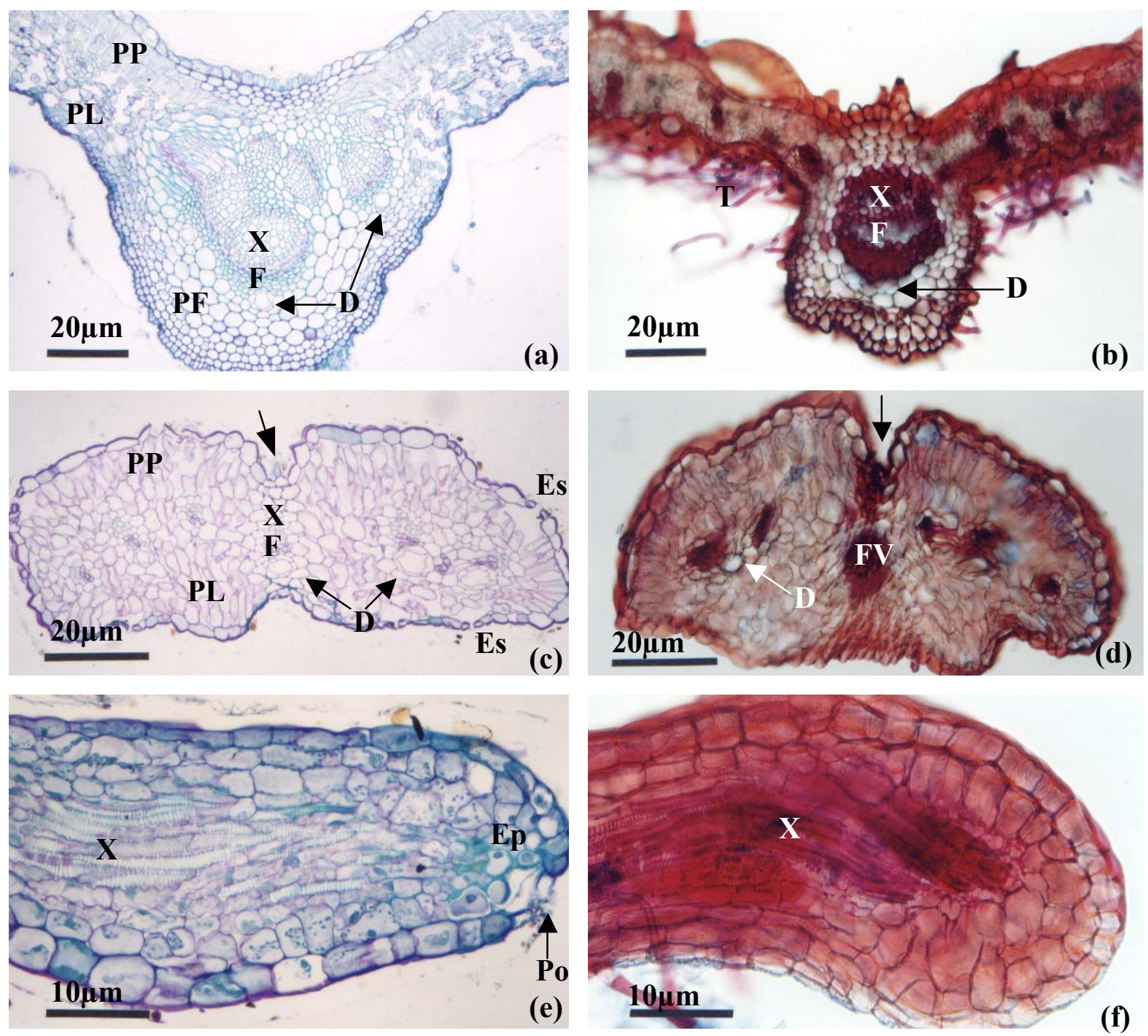

Figura 1 - Cortes da folha de espécies de Senecio. a, c, e. Cortes feitos em micrótomo rotativo com materiais incluídos em metacrilato. $b, d$, f. Cortes feitos à mão livre. a, b. Cortes transversais da nervura central na porção mediana da folha de S. emilioides. c, d. Cortes transversais da porção mediana da folha de S. leptoschizus. e, f. Cortes longitudinais dos dentes na margem da folha de S. stigophlebius. D - ducto; X - xilema; F - floema; Ep - epitema; Pó - poro; FV - feixe vascular; PP - parênquima paliçádico; PL - parênquima lacunoso; PF - parênquima fundamental; T - tricoma; Es - estômato; e Seta - depressão na epiderme adaxial.

Figure 1 - Histological sections of Senecio leaflets. a, c, e. Cross sections were made by using automatic microtome embedding process resin. $b, d$, f. Cross sections were manually made. $a, b$. Midrid cross sections of the medium portion of the leaf of S. emilioides. $c, d$. Cross sections of the medium portion of the leaf of S. leptoszichus. e, f. Longitudinal cuts of the margin teeth of the leaf of S. stigophlebius. D - duct; X-xylem; F-Phloem; Ep - epithem; Po-pore; FV-vascular system; PP palisade parenchyma; $P L$ - spongy parenchyma; $P F$ - ground parenchyma; T-trichomes; Es - stomata; Arrow - depression in adaxial surface. 


\section{AGRADECIMENTO}

À professora Rosane Aguiar-DBV/UFV, pela correção do abstract; às técnicas do Laboratório de Anatomia Vegetal DBV/UFV, Rosane Cruz Portugual e Zilda Alzira Soares, pelo apoio técnico; e à curadoria dos herbários CESJ e OUPR, pela concessão do material. À Capes, pela concessão da bolsa de mestrado.

\section{REFERÊNCIAS BIBLIOGRÁFICAS}

BRIDSON, D.; FORMAN, L. The herbarium handbook 3.ed. Great Brain: Whistable Litho Printers, 1998. 334 p.

CASTRO, M. M.; LEITÃO-FILHO, H. F.; MONTEIRO, W. R. Utilização de estruturas secretoras na identificação dos gêneros de Asteraceae de uma vegetação do cerrado.

Revista Brasileira de Botânica, v. 20, n. 2, p. 163-174, 1997.

CUTLER, D. F.; GREGORY, M. Anatomy of the dicotyledons. 2.ed. Oxford: Clarendon Press, 1998. $324 \mathrm{p}$.

GERLACH, G. Botanische Mikrotechnik. Stuttgard: Georg Thieme Verlag: 1969. 344 p.

JUDD, W. S. et al. Plant systematics: a phylogenetic approach. Massachusetts: Sinauer Associates, 1999. $464 \mathrm{p}$.

METCALfe, C. F.; CHALK, L. Anatomy of the dicotyledons: leaves, stem and wood in relation to taxonomy with notes on economic uses. Oxford: Clarendon Press, 1950. 2 v. 1500 p.
METCALFE, C. F.; CHALK, L. Anatomy of the dicotyledons. Systematic anatomy of leaf and stem, with a brief history of the subject. 2.ed. Oxford: Clarendon Press, 1979. v. 1, 294 p.

METCALFE, C. F.; CHALK, L. Anatomy of the dicolydedons. Wood structure and conclusion of the general introduction. 2.ed. Oxford: Clarendon Press, 1983. v. 2. $308 \mathrm{p}$.

METCALFE, C. F. Anatomy of the dicotyledons. Oxford: Clarendon Press, 1987. v. 3. 223 p.

RADFORD, A. E. et al. Vascular plant systematics. New York: Haper \& Row Publishers; 1974. 891 p.

SCATENA,V. L.; CARDOSO, V. A.; GIULIETTI, A. M. Morfo-anatomia de espécies de Blastocaulon Ruhland (Eriocaulaceae). Acta Botânica Brasílica, v. 13, n. 1, p. 29-42, 1999.

SMITH, F. H.; SMITH, E. C. Anatomy of the inferior ovary of Darbya. American Journal of Botany, v. 29, p. 464$471,1942$.

SOLEREDER, H. Systematic anatomy of the dicotyledons. A handbook for laboratories of pure and applied Botany. Oxford: Clarendon Press, 1908. 2v. 1182 p.

TEIXEIRA, S. P.; CASTRO, M. M.; TOZZI, A. M. G. Secretory cavits and pellucid dots in leaflets of Lonchocarpus (Leguminosae, Papilionoideae, Millettieae). Plant Systems Evolution, v. 221, p. 61-68, 2000.

VIDAL, B. C. Acid glycosaminoglycans and endochondral ossification: microespectrophotometric evaluation and macromolecular orientation. Cell Molecular Biology, v. 22, p. 45-64, 1977. 